\title{
Childhood Overweight and Obesity in Sub-Saharan Africa: Current Definition, Prevalence and Risk Factors
}

\author{
Joel Noutakdie Tochie ${ }^{1 *}$, Aimé Mbonda ${ }^{2}$, Vanessa Fonkwo ${ }^{3}$ and Veronica Aletum ${ }^{4}$ \\ ${ }^{1}$ Department of Surgery and Anesthesiology, Faculty of Medicine and Biomedical Sciences, University of Yaoundé 1, Cameroon \\ ${ }^{2}$ Department of Public Health, Faculty of Medicine and Biomedical Sciences, University of Yaoundé I, Yaounde, Cameroon \\ ${ }^{3}$ Department of Public Health, Catholic University of Central Africa, Yaounde, Cameroon \\ ${ }^{4}$ Department of General Medicine, Elig-Mfomo District Hospital, Centre Region, Cameroon
}

*Corresponding Author: Joel Noutakdie Tochie, Department of Surgery and Anesthesiology, Faculty of Medicine and Biomedical Sciences, University of Yaoundé 1, Cameroon.

Received: June 24, 2019; Published: July 24, 2019

DOI: $10.31080 /$ ASNH.2019.03.0379

\begin{abstract}
Childhood overweight and obesity are one of the most serious public health challenges in the 21st century, with its consequences gradually felt in middle and low-income countries. In this article we discuss the definition, prevalence and risk factors of childhood overweight and obesity in sub-Saharan Africa in a bid to draw up possible preventive strategies to curb the incidence, as well as the morbidity of childhood overweight and obesity in this part of the African continent.
\end{abstract}

Keywords: Obesity; Overweight; Childhood; Sub-Saharan Africa

\section{Introduction}

Childhood overweight and obesity are one of the main global public health challenges of the 21st century, especially in sub-Saharan Africa due to the rising urbanisation and westernised lifestyles (SSA) [1,2]. It is a major risk factor for childhood non-communicable diseases (NCD), in particular, cardiovascular diseases [1]. Several preventive interventions to reduce its incidence over the last three decades have been unsuccessful $[3,4]$.The prevalence of childhood overweight and obesity increased by $47.1 \%$ over the last three decades [3], and it has been estimated that by 2020, an increase of $9.1 \%$ will be recorded [5]. In 2010, about $6.7 \%$ or 43 million (35 million in developing countries) of children under five were either overweight or obese [5]. Furthermore, the prevalence of childhood overweight and obesity in developing countries increased from 8.1 to $12.9 \%$ in boys and from 8.4 to $13.4 \%$ in girls over the last three decades [3], demonstrating the time trend of this rapidly growing epidemic.

Childhood overweight and obesity are worrisome because of its potential long-lasting sequelae in adulthood [6]. If not well-managed in childhood, it could lead to obesity, metabolic, cardiovascu- lar , psychological, malignant complications, and premature death in adulthood [11-14].

In addition, there is a positive correlation between childhood overweight and obesity and the various risk factors for CVD, including atherogenic dyslipidaemia, early and accelerated atherosclerosis, metabolic syndrome, hypertension, type 2 diabetes mellitus and obstructive sleep apnea [11-15]. Determining risk factors for overweight and obesity among children is crucial because childhood is a critical period for the development of obesity in adulthood [16]. These risk factors however, have not been fully examined in overweight and obese children in SSA. In this article therefore, we reviewed the current definition, prevalence, risk factors for childhood overweight and obesity, and possible forms of management in SSA. The overall aim being to draw recommendations to curb the burden of childhood overweight and obesity in SSA.

\section{Definition of childhood overweight and obesity}

Childhood overweight and obesity has been a subject of on-going debate in SSA due to the absence of a standard definition [17]. The assessment of childhood overweight and obesity using body mass index (BMI) may be subject to several draw backs: BMI does 
not differentiate between lean and fat mass, and It varies a lot with respect to gender, growth, and racial background [18,19]. The BMI also has a low sensitivity to detect adiposity [20]. As a result, international limits using percentiles and standard deviations from a median reference point are worldwide preferred to traditional BMI cut-off values of $\geq 30 \mathrm{~kg} / \mathrm{m}^{2}$ and $\geq 25 \mathrm{~kg} / \mathrm{m}^{2}$ for obesity and overweight respectively [21-24]. These international cut-offs were put forth by the WHO, the Centre for Diseases Control and Prevention (CDC), and the International Obesity Task Force. For children and adolescents of age between 5 and 19 years, limits of $\geq 1$ SD and $\geq 2$ SD defines overweight and obesity respectively, based on the WHO criteria [21]. The CDC defines overweight based on cuff-off values between the 85 th to the $94^{\text {th }}$ percentiles and $>95^{\text {th }}$ percentiles for obesity [21]. The Centre for Diseases Control defines overweight based on cuff-off values $85^{\text {th }}-94^{\text {th }}$ percentiles and $>95^{\text {th }}$ percentiles for obesity [23]. Childhood overweight and obesity are defined by the International Obesity Task Force as percentile curve passing though body mass index (BMI) of $25 \mathrm{~kg} / \mathrm{m}^{2}$ at age 18years for overweight and percentile curve passing through BMI of $30 \mathrm{~kg} /$ $\mathrm{m}^{2}$ at age 18 for obesity [24].

\section{Prevalence of childhood overweight and obesity in SSA}

Data from the Demographic and Health Surveys (DHSs) conducted between 2010 and 2014 from 26 SSA countries suggest that 10.7 million children under five $(6.8 \%)$ are overweight or obese [25]. There is a high heterogeneity in studies reporting the prevalence rates of overweight and obesity in under-fives in SSA due to the rapidity of the epidemiologic transition and the large sociocultural differences [17]. In 2013, studies conducted in several SSA countries found that the prevalence of overweight and obesity in children between 5 and 17 years old was $10.6 \%$ and $2.5 \%$ respectively [17].

Risk factors associated with childhood overweight andobesity in SSA

To begin, the gender distribution of overweight and obesity in SSA has a predilection for the female gender. Averagely $7.6 \%$ of boys and $15.4 \%$ of girls between 5 and 17 years old are either overweight or obese in SSA [17]. Higher trends of overweight or obesity in girls from SSA may be explained by the different roles played by each gender; while boys involve themselves in more strenuous physical activities, [26] the girl child in less strainous activity, there is a cultural attachment whereby being overweight or obese is an admired trait for girls in SSA [27].
Secondly, childhood overweight and obesity is very linked to increased physical inactivity of children as a result of indoor activities such as computer games, television viewing and internet $[28,29]$. Many factors contribute to physical inactivity of overweight and obese children in SSA such as urbanisation of cities with resultant lack of open playgrounds in schools and communities, and the persistent emphasis on academic excellence at the expense of physical activity of children [30].

Thirdly, children in SSA are at increased risk of overweight and obesity considering the rightward shift in consumption of traditional healthy foods to high-calorie westernized foods [31]. This diet is rich in saturated fats, refined carbohydrates, and sweetened carbonated beverages, with low levels of polyunsaturated fatty acids and fibres. These predispose them to obesity, metabolic syndrome, type 2 diabetes and coronary artery disease. Furthermore, children of high socioeconomic level are more prone to overweight and obesity compared to those low socioeconomic level in SSA [17,32], probably due to increased sedentary lifestyles and increased accessibility to high-calorie diets which are more affordable to children of high socioeconomic levels.

Still more, some maternal factors seem to play a role in the development of childhood overweight andobesity in SSA. Overweight or obese mothers have a 1.5 to 2 times increased odds of having an overweight/obese child [25,33,34], while children whose mothers have primary education or no formal education have a 1.23 and 1.10 times increased odds of being overweight or obese [25]. This may probably be explained by the fact that less educated mothers may have poor knowledge on high-caloric diets.

Lastly, the birth weights $\geq 4000 \mathrm{~g}$ have been shown in a systematic review [25] and two cross-sectional studies [33,34] to predispose children to either overweight or obesity in SSA.

\section{Conclusion}

The above elucidates the definition, prevalence and risk factors of childhood overweight and obesity in SSA. Interventions to curb the burden of childhood overweight and obesity in SSA should focus on the aforementioned modifiable risk factors: physical inactivity, consumption of high-caloric diets and maternal education. These interventions entail health promotion activities through health education of parents or guardians and children on the illhealth of childhood overweight and obesity. Furthermore, there is 
the need to incorporate a compulsory module on physical activity and healthy diets in schools in SSA. Finally, ministries of education in SSA should work in collaboration with ministries of health to ensure adequate implementation of these public health interventions through the assessment of a reduction in overweight and obesity in children. These policies will go a long way to build sustainable health and educational systems that could help reduce the burden associated with this condition in SSA.

\section{Competing Interests}

The authors declare that they have no competing interests.

\section{Funding}

Not applicable.

\section{Bibliography}

1. WHO. World Health Statistics. (2017).

2. Van der Sande MAB., et al. "Obesity and undernutrition and cardiovascular risk factors in rural and urban Gambian communities". American Journal of Public Health 91.10 (2001): 1641-1644.

3. Ng M., et al. "Global, regional, and national prevalence of overweight and obesity in children and adults during 19802013: a systematic analysis for the Global Burden of Disease Study 2013". Lancet 384 (2014): 766-781.

4. Wang Y and Lobstein T. "Worldwide trends in childhood overweight and obesity". International Journal of Pediatric Obesity 1.1 (2006): 11-25.

5. de Onis M., et al. "Global prevalence and trends of overweight and obesity among preschool children". The American Journal of Clinical Nutrition 92.5 (2010): 1257-1264.

6. Rooney BL., et al. "Predictors of Obesity in Childhood, Adolescence, and Adulthood in a Birth Cohort". Maternal and Child Health Journal 15.8 (2011): 1166-1175.

7. Fung C., et al. 'From 'best practice' to 'next practice': the effectiveness of school-based health promotion in improving healthy eating and physical activity and preventing childhood obesity". International Journal of Behavioral Nutrition and Physical Activity 9 (2012): 27.

8. Reilly J and Kelly J. "Long-term impact of overweight and obesity in childhood and adolescence on morbidity and premature mortality in adulthood: systematic review". International Journal of Obesity (Lond) 35.7 (2011): 891-898.
9. Lawlor D., et al. "Association between general and central adiposity in childhood, and change in these, with cardiovascular risk factors in adolescence: prospective cohort study". BMJ 341 (2010): c6224.

10. The NS., et al. "Association of adolescent obesity with risk of severe obesity in adulthood". Journal of the American Medical Association 304.18 (2010): 2024-2027.

11. Cowan P., et al. "Cardiovascular Risk Factors Increase with Obesity Severity in African American Youth with and without type 2 Diabetes (T2DM)". The American Journal of the Medical Sciences 331.2 (2006): 61-62.

12. Freedman DS., et al. "The relation of overweight to cardiovascular risk factors among children and adolescents: the Bogalusa Heart Study". Pediatrics 103.6pt1 (1999): 1175-1182.

13. Berenson GS., et al. "Association between multiple cardiovascular risk factors and atherosclerosis in children and young adults. The Bogulasa Heart Study". The New England Journal of Medicine 338.23 (1998): 1650-1656.

14. Berenson GS., et al. "Obesity and cardiovascular risk in children". Annals of the New York Academy of Sciences 699 (1993): 93-103.

15. Berenson GS., et al. "Atherosclerosis of the aorta and coronary-arteries and cardiovascular risk-factors in persons aged 6 to 30 years and studied at necropsy (The Bogalusa Heart Study)". American Journal of Cardiology 70.9 (1992): 851-858.

16. Maggisano V., et al. "Adolescence as possible critical window for blood pressure short term monitoring in boys and girls". European Journal of Epidemiology 20.6 (2005): 517-524.

17. Muthuri SK., et al. "Evidence of an Overweight/Obesity Transition among School-Aged Children and Youth in Sub-Saharan Africa: A Systematic Review". PLoS ONE 9.3 (2014): e92846.

18. Flegal KM., et al. "High adiposity and high body mass indexfor-age in US children and adolescents overall and by raceethnic group". The American Journal of Clinical Nutrition 91.4 (2010): 1020-1026.

19. Wellens RI., et al. "Relationships between the Body Mass Index and body composition". Obesity Research 4.1 (1996): 35-44.

20. Neovius M., et al. "BMI, waist-circumference and waist-hip-ratio as diagnostic tests for fatness in adolescents". International Journal of Obesity 29.2 (2005):163-169. 
21. WHO [homepage on the Internet] Child growth standard (2006). http://www.who.int/childgrowth.

22. Butte NF., et al. "Evaluation of the feasibility of international growth standards for school-aged children and adolescents". The Journal of Nutrition 137.1 (2007): 153-157.

23. Kuczmarski RJ., et al. "CDC growth charts: United States". Advanced Data 314 (2000): 1-27.

24. Cole TJ., et al. "Establishing a standard definition for child overweight and obesity worldwide: international survey". BMJ 320 (2000): 1240-1243.

25. Gebremedhin S. "Prevalence and differentials of overweight and obesity in preschool children in SubSaharan Africa". BMJ Open 5 (2015): e009005.

26. Nyawornota V., et al. "An Exploratory Study of Physical Activity and Over-Weight in Two Senior High Schools in The Accra Metropolis". Ghana Medical Journal 47.4 (2013):197-203.

27. Steyn K and Damasceno A. "Lifestyle and related risk factors for chronic diseases". In: Jamison DT, Feachem RG, Makgoba MW, et al., editors. Disease and mortality in Sub-Saharan Africa. 2nd edition [mongraph on the internet]. Washington, DC: World Bank (2006).

28. Tremblay MS., et al. "Systematic review of sedentary behaviour and health indicators in school-aged children and youth". International Journal of Behavioral Nutrition and Physical Activity 8 (2011): 98.

29. Popkin BM. "The nutrition transition and obesity in the developing world". The Journal of Nutrition 131.8 (2001): 871S873S.

30. Guptha N., et al. "Childhood Obesity in Developing Countries: Epidemiology, Determinants, and Prevention". Endocrine Reviews 33.1 (2012): 48-70.

31. Misra A and Khurana L. "Obesity and the metabolic syndrome in developing countries". The Journal of Clinical Endocrinology and Metabolism 93.11-1 (2008): S9 -S30.

32. Fruhstorfer BH., et al. "Socio-economic status and overweight or obesity among school-age children in sub-Saharan Africa a systematic review". Clinical Obesity 6.1 (2016):19-32.
33. Tchoubi S., et al. "Prevalence and Risk Factors of Overweight and Obesity among Children Aged 6-59 Months in Cameroon: A Multistage, Stratified Cluster Sampling Nationwide Survey". PLOS ONE 10.12 (2015): e0143215.

34. Gewa CA. "Childhood overweight and obesity among Kenyan pre-school children: association with maternal and early child nutritional factors". Public Health Nutrition 13.4 (2010): 496503.

Volume 3 Issue 8 August 2019

(C) All rights are reserved by Joel Noutakdie Tochie., et al. 